\title{
Factors influencing people's ability to maintain their activity levels during treatment for soft tissue sarcoma - a qualitative study
}

Sarah Dewhurst MSc MCSP, Physiotherapist, The Royal Marsden NHS Foundation Trust, London, SW3 6JJ, UK. crightonsarah@yahoo.co.uk

ORCiD identifier 0000-0002-8631-7556

Ruth Tigue MSCP, Physiotherapist The Royal Marsden NHS Foundation Trust, London, SW3 6JJ, UK. ruth.tigue@rmh.nhs.uk

ORCiD identifier 0000-0002-8631-7556

Cathy Sandsund MSc MCSP, Allied Health Professional Researcher, The Royal Marsden NHS Foundation Trust, London, SW3 6JJ, UK.

catherine.sandsund@rmh.nhs.uk

ORCiD identifier 0000-0002-8898-9022

Gill Mein RRGN, RGM, HV, MSc, Senior Lecturer in Health and Wellbeing, Faculty of Health, Social Care and Education, St George's University of London and Kingston University, Cranmer Terrace, London SW17 ORE.

G.Mein@sgul.kingston.ac.uk ORCiD identifier 0000-0002-0421-8811

Clare Shaw PhD RD, Consultant Dietitian and Therapies Research Lead, The Royal Marsden NHS Foundation Trust, London, SW3 6JJ, UK. clare.shaw@rmh.nhs.uk ORCiD identifier 0000-0003-4169-9391 


\section{ABSTRACT}

Soft tissue sarcoma is a rare connective tissue cancer treated with chemotherapy in the advanced stages. Emerging evidence suggests that physical activity improves symptom management and quality of life for people undergoing chemotherapy for advanced cancer. However, little research reports their perspective. Semi-structured interviews were used within a phenomenological approach to explore factors that affect people's ability to be physically active while undergoing treatment. Six participants were recruited with purposive sampling. Thematic analysis was used to analyse the data. Three themes identified that physical activity was seen as an indicator of a persons' own sense of normality; a feeling of loss and uncertainty for the future had impacts on peoples' ability to be physically active, finally, participants found it challenging to recognise their support needs as their activity levels reduced. Motivation to remain active was individual and numerous barriers affected participants' ability to remain active as their disease advanced, this included a lack of specific guidance whilst undergoing chemotherapy. Participants expressed uncertainty generally in identifying and expressing their support needs as they faced multiple complex issues. Health professionals should be proactive exploring possibilities for physical activity to mitigate the expected physical decline and support symptom management while undergoing palliative chemotherapy.

Key Words: soft tissue sarcoma, physical activity, chemotherapy 


\section{INTRODUCTION}

Sarcoma is a collective term for malignancies affecting connective tissue (Kwong, Furtado, and Gerrand, 2014) and there are two broad sub types: soft tissue and bone. With just 3,272 new cases diagnosed in the UK in 2010 (CRUK, 2017), lack of knowledge about soft tissue sarcoma (STS) in the wider population means that diagnosis is often delayed and the disease can be widespread before treatment starts (Schreiber et al, 2006). This has an adverse effect on survival rates (Tobias and Gillis, 2014), with only 45\% of people diagnosed in England expected to survive STS for 10 or more years (CRUK, 2017). At the point of diagnosis many people with STS have incurable disease and their only treatment option is chemotherapy with palliative intent, aimed at reducing symptoms and prolonging life (Tobias and Gillis, 2014).

People are often debilitated both from the disease process itself and from the side effects of treatments which may be on-going for the duration of their survival. The symptom burden includes fatigue, weight gain, muscle loss, peripheral neuropathy and cardio-toxicity, as well as functional impairments and pain depending on where the STS is sited (Granda-Cameron, Hanlon, Lynch, and Houldin, 2011). There is a need for rehabilitation and supportive care interventions to help minimise the impact the disease and the treatment side effects have on quality of life and societal participation (NHS England, 2016). All-cause mortality in cancer survivors tends to decrease with increasing amounts of exercise (Lemanne, Cassileth, and Gubili, 2013). Emerging evidence shows that physical activity (PA) is well received, safe and beneficial, helping to improve quality of life, physical performance and minimise the side effects of people treated for advanced cancer (Cheville et al, 2013; Heywood, McCarthy, and Skinner, 2018; Millbury et al, 2015; Quist et al, 2006; Quist et al, 2012;) . Furthermore, Jones et 
al (2012) reported functional capacity to be an independent predictor of survival $(p=0.003)$ in people with advanced lung cancer with a $13 \%$ risk reduction of death associated with each $50 \mathrm{~m}$ incremental increase in six meter walking test distance achieved. Exercising whilst receiving chemotherapy treatment has recently been shown to help preserve skeletal muscle (Mijwel et al, 2018). There is strong evidence now that increased levels of muscle function and functional exercise capacity are associated with positive disease mediation, however, optimal dosing is as yet unclarified and the research focus is now on factors such as disease specific type, quantity and intensity of exercise prescription (Jones et al, 2012). 


\section{$\Rightarrow$ CONSORT \\ TRANSPARENT REPORTING Of TRIALS}

Figure 1 CONSORT 2010 Flow Diagram

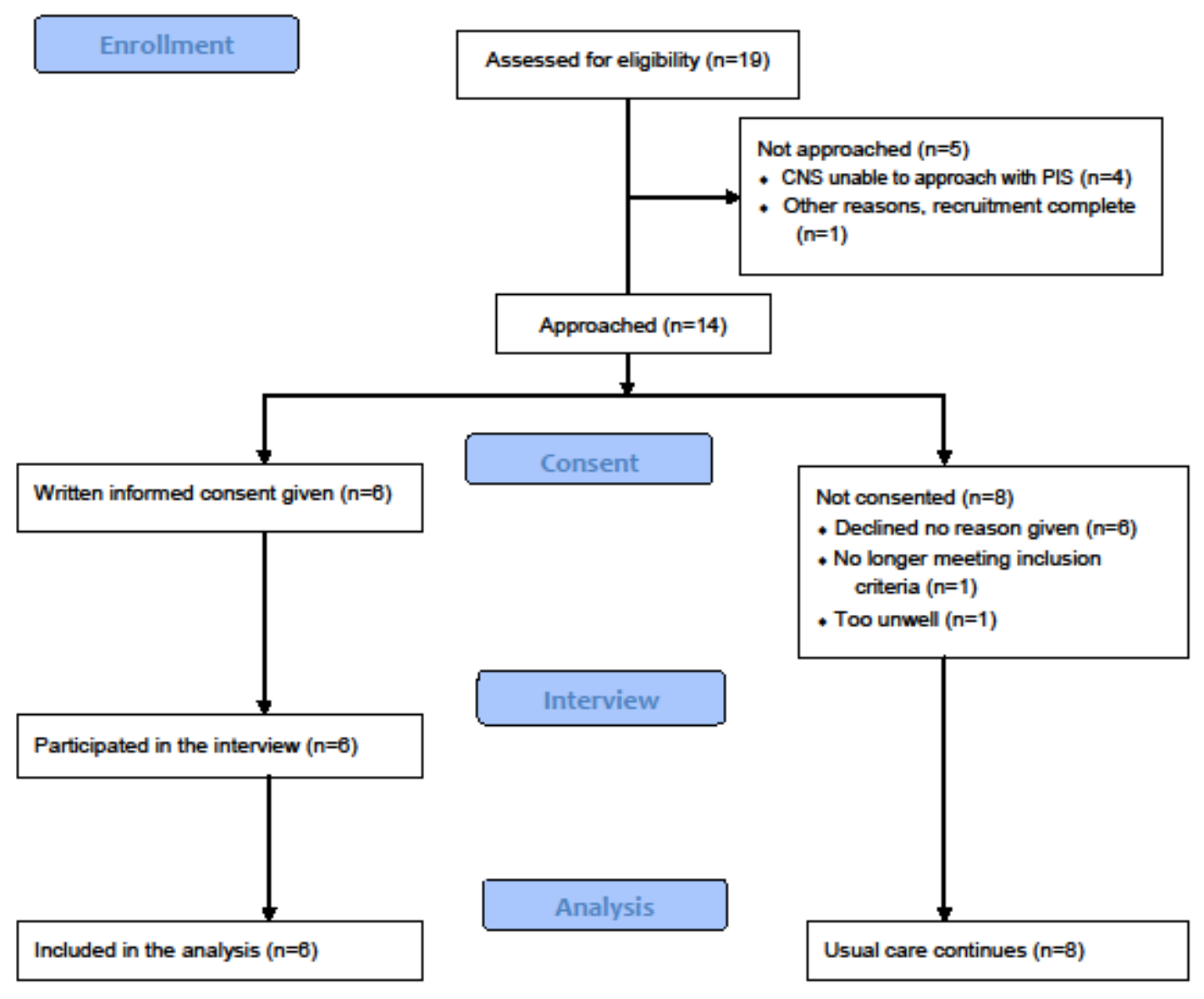


Despite this, the amount of physical activity people undertake declines as soon as people are diagnosed with cancer, even when people were very active prior to their diagnosis (Blanchard et al, 2003; Irwin et al, 2003). Barriers to remaining active have been identified in people with advanced lung cancer by Cheville et al. (2017) but similar research has not been undertaken with STS. Many people with cancer have rehabilitation needs (Holm et al, 2012), however the diverse range of presentations and the relatively small numbers means there is very little research into STS and any aspect of rehabilitation. In addition, the patient experience regarding physical activity and support needs has not been captured. As a result, supportive interventions for people with STS are currently informed by research based on commoner cancers such as breast and prostate so may not be meeting their specific needs.

The aim of this research was to explore factors which might influence the physical activity people with a STS undertake as they receive palliative chemotherapy, based on their own perspective. The study was guided by four objectives: 1) Investigate how people with a STS feel their physical activity levels are affected during chemotherapy treatment; 2) Explore factors which might prevent people with a STS from maintaining their usual levels of physical activity during chemotherapy treatment; 3) Discover whether people with a STS are aware of the benefits of remaining physically active during chemotherapy treatment; and 4) Identify any means of support this group of patients would find beneficial in supporting their physical activity goals during chemotherapy treatment

\section{$\underline{\text { METHOD }}$}

\section{Design, Theoretical Framework and Ethics}


In order to understand the lived experience of people going through treatment we used an inductive constructionist approach from the phenomenological paradigm. Semi-structured interviews were completed using a topic guide to address the objectives. The study is reported according to COREQ guidance (Tong, Sainsbury, and Craig, 2007). (Blinded) Ethical approvals were received from Scottish Borders REC 14/NS/1016 before data collection started.

\section{Sample Size and Recruitment}

Eligible participants were identified from outpatient clinic lists at the oncology centre and were purposively sampled according to the eligibility criteria (Table 1.). A pragmatic approach to sampling was adopted regardless of previous levels of physical activity or co-morbidities to reflect a clinical population. The sample size was pre-selected as six in order to work within available resources for the project at its initiation, and in recognition of the specialist nature of the population (Malterud K, Siersma VD, and Guassora AD, 2016; Varpio et al, 2017).

During recruitment, potential participants were given an information sheet by the Sarcoma Clinical Nurse Specialists when they attended an outpatient appointment. If people gave verbal consent the primary researcher made telephone contact to answer any questions and arrange an interview date to coincide with their second cycle of chemotherapy. For participants' convenience the interviews were completed on a day when they were attending the hospital. Informed, written consent was sought immediately prior to the interview. Participants were free to withdraw consent at any time throughout the study. 


\section{Data Collection and Setting}

Six face to face interviews were undertaken by SD or RT, lasting between 24 and 54 minutes. The study was conducted between November 2014 and December 2016. Both female interviewers were employed by the Oncology Centre as Physiotherapists and had worked within the Sarcoma Team. SD has a special interest in exercise and cancer rehabilitation and has worked on several initiatives to help promote the awareness of the benefits of remaining

physically active amongst people with cancer.

\section{Table 1. Eligibility Criteria}

Inclusion criteria

Participants will:

1. have a diagnosis of a soft tissue sarcoma

2. be receiving first line chemotherapy treatment at the Trust's Sarcoma Unit 3. be willing and able to articulate their experience in English
Exclusion and withdrawal criteria

\section{Participants will not:}

1. have a performance status $>2$ indicating they are more symptomatically unwell and therefore unlikely to complete 2 cycles of chemotherapy

2. be under 18 years

3. have had previous chemotherapy for soft tissue sarcoma i.e. be on second or third line treatment as they are more likely to be symptomatic from progressive disease

4. be above the age of 70 as they are more likely to have age related co-morbidities influencing their physical activity levels

5 . have been previously treated by the researcher as it might bias their responses to questions related to physical activity 
The interviews took place at the Oncology Centre and followed a semi-structured topic guide which was used flexibly to allow for discussion of points important to participants. The topic guide was reviewed by the Chief Executive of Sarcoma UK.

Interviews were audio-recorded and field notes were also taken immediately following the interview. The interviews were transcribed verbatim by the lead researcher for the first three interviews and by an independent transcriber for the final three. Participants were offered the opportunity to review the content of their interview after transcription but none chose to do so. 
Table 2. Participant characteristics

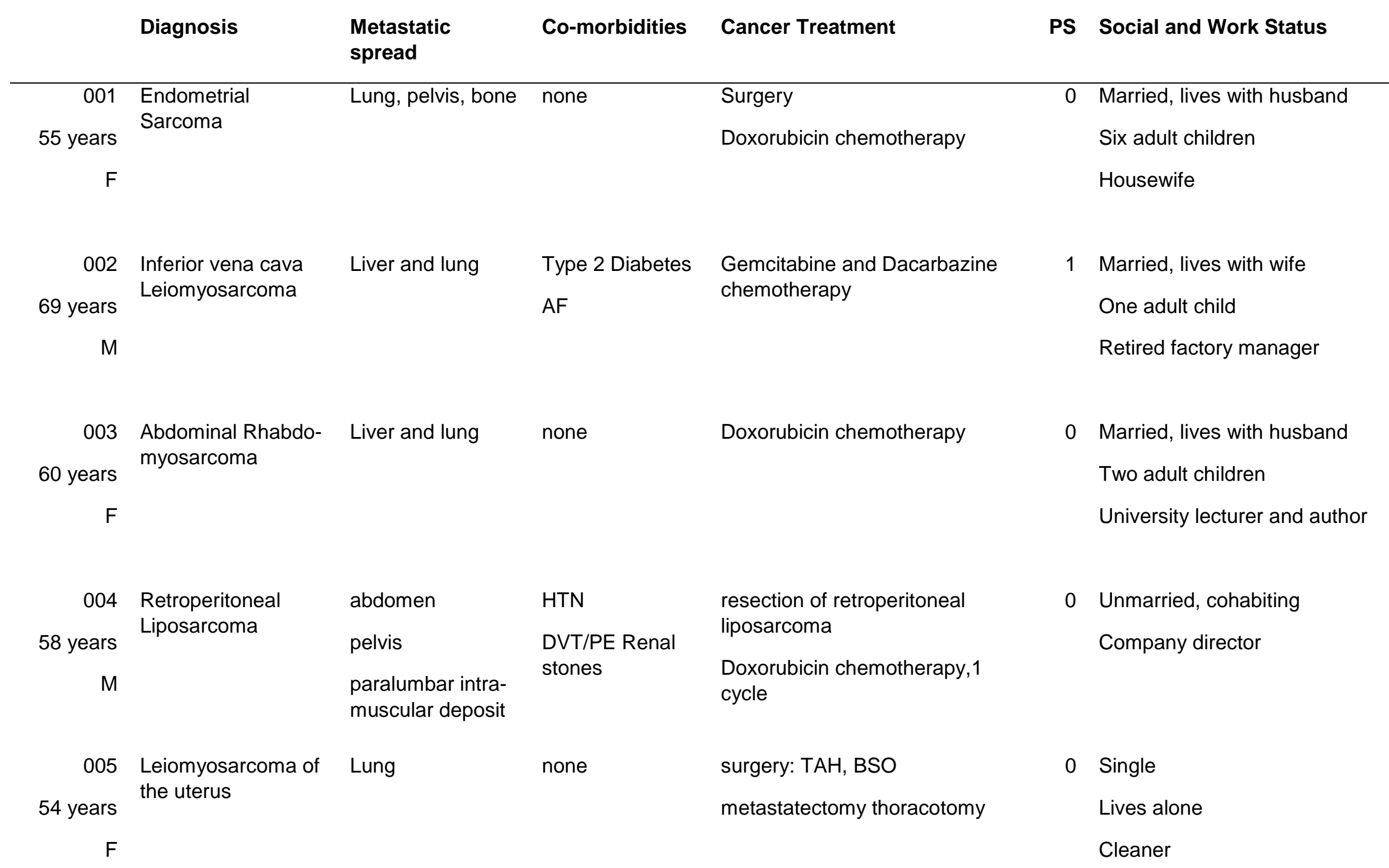


Doxorubicin chemotherapy, 1

cycle

006 Pleomorphic spindle Lung cell sarcoma

53 years adrenal gland

$\mathrm{F}$
Type 2 diabetes

HTN
Left adrenalectomy/
nephrectomy

Doxorubicin chemotherapy, 1

cycle

\section{Married}

Lives with husband

Cleaner

Key: PS: Performance Status (Oken et al 1982); M; Male; F: female; DVT: Deep vein thrombosis; PE: pulmonary embolus; TAH: total abdominal hysterectomy; BSO: bilateral salpingo-oophrectomy; AF: atrial fibrillation; HTN: hypertension

Table 3. Themes and sub-themes developed from the interview data

\begin{tabular}{|l|c|}
\hline Theme & Sub-theme \\
\hline Physical activity as an indicator of normality & B. Being physically active allows you to fulfil your role physically active is part of daily life \\
\hline & C. Being physically active is beneficial to physical and \\
mental wellbeing
\end{tabular}




\section{Data Analysis}

A largely inductive approach based on a constructionist perspective was used in the analysis, where the authors derived themes primarily from the data itself rather than from pre-existing theory (Green and Thorogood, 2014; Varpio, 2017). Analysis was conducted after each interview with coding in the transcript margins initially completed by SD who then used flip chart paper to derive the resultant themes. It was felt that data saturation was reached as no new themes were created after the fifth interview. A workshop session was then undertaken with SD, RT and CAS to discuss the themes and review the entire dataset to ensure rigour and reflexivity. The field notes were used at this point to inform the researchers' interpretation of the data. Lastly the themes and supporting quotations were confirmed by GM who is an experienced applied health researcher with qualitative methodologies.

\section{FINDINGS}

Three themes were derived from the data:

1. Physical activity as an indicator of normality

2. The implications, loss and uncertainty for the future

3. The challenge of recognising support needs as physical activity declines 
Theme 1: Physical activity as an indicator of normality

i. Being physically active is part of daily life

All of the participants reported a strong connection with being active, describing it as "an important part of life" and they had all lived active lives prior to their diagnosis.

"I was very active, always always busy, always doing several things at once" (003)

"I like to be active. I was all my life and I don't want to be stay at home and sit watching television" (005)

And when reflecting on how life has changed, one of the participants stated:

"Yes but as somebody who likes being outside and doing things outside, not being able to do the things I normally would, yeah it's [the diagnosis] had quite a big impact" (001)

suggesting that being active was an integral part of life rather than something she made herself do.

Despite leading active lives none of the individuals participated in structured exercise such as going to the gym, and did not use the term 'exercise' when talking about their former lifestyles. Only one participant enjoyed organised sport, in this case sailing, but was quick to point out that:

"Yeah, I'm not and never have been a regular exerciser as such in terms of you know gym or walking or swimming. But l've always been active in terms of I go sailing most weekends" (004) 
ii. Being physically active allows you to fulfil your role

The female participants considered being active as critical to their role as mothers.

This motivated them to keep active and maintain a sense of control in order to fulfil this role for as long as possible and protect their family from signs of their illness.

"and also from the point of view of having the children around, you see my children they're always around and I think well I can't just be seen to be giving in, I've got to be seen to be normal" (003)

Another participant stated:

"you try and put on a brave face and you keep going because of them and then maybe you do a bit too much and you know instead of sort of, um because you don't want to upset them" (001)

The participants were concerned about the affect their physical limitations might have on their families. The motivation created by this protective maternal instinct to maintain a sense of one's own normality and remain active is clear:

"when somebody tells you you have cancer, normality flies out of the window, I want to keep things as normal as possible for them, you know, my youngest son is in the last year of his degree and I don't want this to affect his results, um my other son is working but he has um emotional mental anxiety difficulties and I don't want to burden him with too much anxiety so it's important to try and keep as close to normality as possible" (003) 
The ability to be physically active also impacted on the participants' roles in the workplace. Three of the four participants who worked felt they needed to be active in order to do their jobs, commenting:

"I had to be active and I have to still, and have to be in good condition because I'm working as a cleaner at this quite hard, physical work" (005)

"You know I might be on my feet all day long teaching. I mean I always think of my life as literally running from one university to another" (003)

These participants were all very motivated to return to work as soon as possible and their beliefs about physical activity were closely linked to their desire or need to work as they would not be able to perform their role if they lost their fitness as a result of treatment.

More generally, being active also offered the participants a way of affirming their role as a physical being, giving them a sense of capability and in some cases affirming their masculinity. One of the male participants measured his recovery from surgery by being able to drive the rescue boat and pick up capsized sailors. He took pride in his role within the sailing club and acknowledged the physical strength that this required.

iii. Being physically active is beneficial to physical and mental wellbeing Participants gave many reasons why they felt being active was beneficial for both physical and psychological wellbeing: 
"Um well I think certainly for me, being outside is very important. I do tend, I don't suffer from or call it depression at all but I do feel quite down sometimes, particularly in the winter months but I've found for a number of years now if I can get out, in the fresh air or walk outside a bit or do a bit of gardening whatever, it lifts my spirits," (001)

There was a sense that going outside allowed participants to connect with the outside world and their former 'well' self, with one individual stating:

"well it makes you feel more normal, going to the shops or just walking" (003)

The participants also reflected on the emotional benefits of being active:

"It's the fresh air, it's the exercise um my wife thinks I'm mad but I enjoy walking alone as well you know you can just sort of walk along and think about anything and just get the brain going a bit sometimes." (002)

Similarly, another participant described being active as feeling like she had control over her illness:

"Because I just think when you're more active you cope with things. I don't want to get to the position where I can't do this and I can't do that. And then you kind of go down" (006) As did another participant in relation to controlling the side effects:

"I think I'm just going to perhaps try a slightly different strategy in the next week or so and maybe just drag myself out for an hour. Sort of walk around, you know round the block a few times or something just to try and not give in to feeling tired and listless all the time" (004) 
The participants recognised that keeping active was empowering and demonstrated

a belief that giving in to a more sedentary lifestyle would let the disease take hold.

Another participant highlighted the social benefits of being active as sailing underpinned his social life and he enjoyed the sense of challenge and competition. The participants believed activity allowed them to maintain a sense of normal life, reduce their symptoms, increase their energy levels and feel in control.

Theme 2: The implications, loss and uncertainty for the future

Many participants had a prolonged period of uncertainty involving different hospitals and multiple investigations prior to their diagnosis:

"It [the diagnosis] was very uncertain and that was the shock." (003)

This sense of shock resonated with all the participants, with another describing going into hospital for a routine operation and finding out she had cancer. She stated she had "no idea' that her symptoms represented a life limiting illness and the suddenness of the diagnosis was traumatic.

Participants were also living with uncertainty surrounding their treatment options and prognosis:

"So at the moment there's very limited information from previous kind of treatment as to whether this will be successful or not." (004) 
Participants' experience of previous treatment influenced their confidence and expectations. Typically their recovery from surgery went better than they anticipated and they were able to return to normal activities quite quickly; in contrast once they started undergoing chemotherapy they started to feel worse and it started impacting on their ability to be physically active:

"In fact until the start of the chemotherapy three weeks ago I wasn't ill as such you know the kind of slightly odd thing now is it's the chemotherapy is definitely making me feel worse" (004)

There was a sense that participants felt more unwell after starting chemotherapy and experienced debilitating fatigue:

"You just have no energy, it's not that you want to sleep particularly it's just you feel as though your legs won't get you there you know it's just this feeling that you know that you're not going to make it." (001)

Feeling unwell reduced their physical ability and impacted on their function, for example:

"Um I'm having to accept help with the housework because it's I just you know I mean I'm keeping the basics done um and that would be fine but you know I've got quite a big family and the church are very helpful and they're helping me out I just can't do all the things I would normally do." (001)

Uncertainty around how they might feel after treatment also affected their views on returning to work: 
"I don't know if I will be able to work after more chemo cycles because it was, I went after the first to work but it was very hard. I don't know how I stood on my feet, but I did it" (005) "I don't know how I'll feel once the chemotherapy ends, I just don't know I um you know if I carry on feeling like I'm feeling I probably could go back and do some teaching, it would probably be easier than I think it's going to be whether I'll feel the way I used to l've no idea I just don't know" (003)

One of the challenges participants found was managing the variability in their symptoms, "I mean every day is different" as one participant mentioned, which is typical of chemotherapy treatment and makes it difficult for patients to adhere to a routine or confidently plan ahead. This quotation

demonstrates the frustration:

"So some days have been, you know felt pretty good, I've been able to do stuff, go out. You know feel fairly normal. I've been sailing a couple of times. But then I'd find that I needed a couple of days

where I'd just do very little, sleep a lot. And then the last ten days, well no, seven days I've not really felt up to doing very much at all. I've felt very tired, quite weak, quite light headed. So, Yeah I've done very little in the last week." (004)

This pattern of enforced inactivity and sedentary behaviour is in contrast to the active picture that the participants painted of themselves prior to their diagnosis. The participants 
were only receiving their second of potentially six cycles, however, they already express a sense of fear for how they

may feel by the end and increasing anxiety in their physical capabilities:

"Well I think if the chemo doesn't work then that's the inevitability because the tumour's just growing so quickly, that eventually I think I'll be bedridden" (004)

They were concerned about the cumulative effect of treatment side effects, but also associated a decline in function with deterioration in their overall health. One participant stated:

"I think, I think that just the fact that I couldn't be physically active it would be I don't know really it's er it's the sort of I think it'd too glib to say it would be the beginning of the end sort of thing but it would maybe in my mind be something like that - I feel all the time I can be active and keep going I know I'm trying to fight this thing you know and er if I couldn't do that, um I think I would be worried." (002)

This quotation illustrates the perception that reducing activity levels when you are fighting a terminal disease may represent a deterioration in your condition. None of the participants openly talked about the palliative nature of their disease, but they referred to keeping active and doing normal things as being reassuring that they were remaining well. The future and their role in life appeared compromised by decreasing activity levels, reduced confidence and increasing anxiety regarding disease progression. 
Theme 3: The challenge of recognising support needs as physical activity declines

The participants reported they had not received much information regarding physical activity whilst receiving chemotherapy. Two participants referred to being given a Macmillan booklet and one mentioned receiving general advice to keep active from the medical team but there was still uncertainty:

"I did ask about exercise and they said it was important, I wasn't sure whether they meant like um going to the gym or just you know not sitting on the settee all day - I wasn't quite sure about the level of exercise I should do" (003)

"I'm still really very unsure about what I should or shouldn't be doing as far as being active" (006)

Although the participants all reported feeling debilitated by the fatigue, they had not been offered specific support to help them manage it, nor had they requested any.

One of the participants reported she felt fatigue was not a serious enough complaint to bring up with her medical team:

"I think partly you're almost a bit embarrassed to discuss tiredness because it sounds so silly" (001)

She also said she would have found it easier to discuss how the fatigue was affecting her if she had been asked about it directly. 
Interestingly, only one of the participants felt they required support to help them with symptoms or to maintain their activity levels, saying advice on how much she could manage would be helpful.

"oh information, any information to help me where I am now as to regards to what I can do or what I should or shouldn't do" (006)

Three participants reported they may need more input from health professionals in the future if things changed. And two participants wondered whether frailer or older patients might need a greater level of support than themselves. Peoples' openness to advice is clearly individual with one of the participants stating:

"No I don't take much notice of all that official guidance" (004)

Whereas another participant said:

"I listen to advice and I act upon it" (006)

\section{DISCUSSION}

Much emphasis is now placed on how being active can reduce both disease symptoms and the side effects of cancer treatment, however, the functional benefits of exercise are not as widely discussed but may be of more importance to people with advanced disease than clinicians are aware of (Cheville et al, 2017; Gralla et al, 2014). There are significant barriers preventing cancer patients from maintaining an active lifestyle (Blaney et al, 2010). 
Understanding individuals' motivations and practical goals is key to their successful rehabilitation at every stage of the disease. This study provides insight into peoples' attitudes towards physical activity as they receive palliative chemotherapy treatment for STS.

The interviews tell a progressive story of participants leading busy, vital lives before the shock of a terminal diagnosis and treatment toxicity undermines confidence in their physicality. As theme one, 'indicator of normality' demonstrates, all of the participants described how an active lifestyle had been part of their normal social and role functioning prior to their illness. All of the participants were clear about the health and wellbeing benefits of being active. The psychological benefits of activity are well documented (Knapen, Vancampfort, Moriën , and Marchal, 2015) and exercise prescription is now commonplace in the management of mental health conditions. Twenty five percent of people living with a cancer diagnosis have an unmet mental health need (NHS England, 2014) and without any specific advice, the participants described how keeping active helped them all psychologically.

The participants reported that being physically active simply made them feel better and more able to cope. Researchers studying groups of people with other advanced cancers report similar benefits to symptoms, physical function and participation. Adamsen et al. (2012) interviewed patients undertaking chemotherapy treatment for advanced lung cancer and reported an improved sense of emotional wellbeing, strength, physical fitness and vitality despite significant levels of fatigue. This was borne out by adherence levels of $76 \%$ to 
a structured exercise programme. In addition, a feasibility study by Hoffman et al. (2013), based on seven participants following surgery for lung cancer achieved a $96 \%$ rate of reported adherence to a home balance and exercise programme designed to address fatigue. Participants expressed that the programme gave them 'a lot of strength' so that they 'could keep going'. Conversely in our study, participants did not report exercise helped them to cope with fatigue but that this symptom was the biggest barrier to maintaining previous activity levels, highlighting the importance of education around the management of fatigue.

Managing physical health wasn't a commonly reported benefit in this study. However, living with a long-term condition increases the incidence of cancer and this patient group often experiences a complex health picture so, keeping physically active is of proven benefit (Macmillan, 2015). It is significant that this was not raised more commonly as a motivating factor in this study and its omission might indicate that the message of the importance of physical activity for physical health is not reaching people treated for advanced cancer.

Theme one 'physical activity as an indicator of normality', also demonstrated how each individual's approach to activity is highly personalized, based on many factors including their preferences, lifestyle, age, family status and in some cases economic position. Whilst traditionally a standardised exercise programme might have been prescribed, these findings suggest that it is paramount that health professionals adopt an individualised approach and understand the factors which influence people's activity preferences and inherent motivation. 
The first theme 'physical activity as an indicator of normality' suggests that appreciating people's roles whether in a family, at work or on a wider social level may provide a useful insight into someone's motivation to remain or return to activity. This individualised approach to maintain participation, is supported by Maddocks and Granger (2017) work using the Goal Attainment Scale in the palliative care setting.

Significantly, none of the participants referred to the term 'exercise'. Despite being very vocal about the benefits of being active, these participants were not active gym attenders, and only one of them participated in organized sport. Using the term activity instead of exercise might prevent health professionals from alienating patients and allow a dialogue about the benefits of activity to occur. The specific dose response to activity levels and the benefits to people with advanced cancer continues to be explored by researchers and is currently unclear in this population (Cheville et al, 2017).

Studies have shown that being active as opposed to completing regular exercise is sufficient to reduce the health risks of a sedentary lifestyle and therefore activity on any level should be encouraged (Ekblom-Bak et al, 2012).

Recognising that motivation to be active comes from enabling a return to function rather than a sporting goal permits rehabilitation professionals to approach conversations with patients in a different way. Asking patients about the functional impairments they are experiencing rather than their symptoms might be more insightful. This is supported by use of the WHO-ICF domains regarding activities and participation, and needs to be addressed arguably more directly than subjective quality of life measures (Bayly, Wilcock, Higginson, 
and Maddocks, 2017). These can be used to direct conversations, enhance motivation and work meaningfully towards shared goals (Maddocks and Granger, 2017).

This approach may also allow individuals to recognise that they may benefit from support, as our findings showed that participants were unlikely to declare their functional limitations in medical consultations. During the interviews this group of highly motivated people all freely discussed the limiting effects the sarcoma and treatment had on their ability to remain active but theme three demonstrates they did not recognise they might require support and had not brought these issues up in medical consultations. Perhaps they did not directly link their symptoms to their reduced function; or as suggested by Wagland et al, (2016) patients with advanced cancers might downplay their symptoms fearing a negative impact on further treatment being offered if their performance status seems compromised. In some cases the interview process appeared to be the first time participants had verbalized the impact that the physical restrictions both the disease and the treatment had inflicted; and there was a process of realization as people talked about their experience. Given that patients tend to under-report fatigue (Bayly, Wilcock, Higginson, and Maddocks, 2017) and rely on their own support mechanisms to cope, this poses a challenge to health professionals in a busy clinical setting.

Participants discussed the change in routine as they underwent chemotherapy and their perception that increasing inactivity symbolized their lives moving away from normality towards something unknown. Several barriers to remaining active were mentioned throughout the interviews but the unknown nature of both the illness and the treatment 
seemed to be the biggest deterrent and is likely to significantly influence people's ability to commit to acting on advice regarding physical activity.

There were also reports that there had been clear guidance from health care professionals at some parts of the treatment, i.e. following surgery, but guidance seemed less clear during chemotherapy. It is our responsibility to educate, however informing people in a timely, sensitive way is a challenge, and the participants in this study had differing views as to how much information they wanted to know. Activity on any level should be encouraged by all clinicians, even if they are not experts in rehabilitation, since the content of medical consultations is influential for patients and their families (Macmillan 2016).

\section{Strengths and Limitations}

The small sample size clearly limits the generalisability of the findings however its main strength is that it is the first exploration of physical activity with this rare population group and the findings are supported by larger studies in other palliative populations. A second potential limitation with this study is that all of the participants had an interest in activity and were physically motivated people. This study does not therefore provide insight into the views or support needs of people who are not leading active lives at the point of treatment.

We attempted to limit the inherent bias of the lead interviewers being experts in the field of physical activity and oncology by using a topic guide approved by the chief executive of the 
leading sarcoma charity and ensuring that the participants had not had previous clinical contact with the researchers. However, in the interests of transparency, we acknowledge that despite the robust process adopted for the analysis, the interpretation of the data in any qualitative research is coloured by the researchers' underlying beliefs and experience.

\section{CONCLUSION AND CLINICAL IMPLICATIONS}

The clinical and social situations become increasingly complex for people living with advancing disease. In this study the participants' relationships with exercise were described based on their experience as healthy individuals and used to maintain their sense of normality, self and role. Physical activity levels reduced during chemotherapy primarily due to fatigue, uncertainty surrounding the impact of treatment and unclear guidance from health professionals. Participants expressed regret that they were no longer able to perform to the same level and uncertainty about the risk this posed to fulfilling their roles.

This suggests there is a gap in their knowledge of the health benefits gained by continuing to be active as they undergo treatment and the support that might be available to them. Proactively investigating individual's own goals and utilising their activity habits therapeutically might help clinicians to address some of the uncertainty patients face, manage their symptom burden and promote a more positive hopefulness. 
Key Learning Points:

- Be proactive and predictive in assuming physical activity levels will decline

- Initiate conversations about symptoms and their impact on function and role

- From diagnosis onwards, encourage activity and participation, not necessarily "exercise"

- All MDT members must share a consistent approach 


\section{References}

1. Adamsen L, Stage M, Laursen J, Rorth M, Quist M 2012 Exercise and relaxation intervention for patients with advanced lung cancer: a qualitative feasibility study. Scandinavian Journal of Medicine \& Science in Sports 22: 804-15.

2. Bayly J, Wilcock A, Higginson IJ, Maddocks M 2017 Early Engagement in Physical Activity and Exercise Is Key in Managing Cancer Cachexia. Oncology 31: 38-39 Williston Park NY.

3. Blanchard CM, Denniston MM, Baker F, Ainsworth SR, Courneya KS, Hann DM, Gesme DH, Reding D, Flyn T, Kennedy JS 2003 Do adults change their lifestyle behaviours after a cancer diagnosis? American Journal of Health Behaviour 27: 246-256.

4. Blanchard CM, Courneya KS, Stein K 2008 Cancer survivors' adherence to lifestyle behaviour recommendations and associations with heath related quality of life: results from the American Cancer Society's SCS-II. Journal of Clinical Oncology 26: 2198-2204.

5. Bland KI 1997 Quality-of-life management for cancer patients. CA - A Cancer Journal for Clinicians 47:194-197. 
6. Blaney J, Lowe-Strong A, Rankin J, Campbell A, Allen J, Gracey J 2010 The cancer rehabilitation journey: barriers to exercise among patients with cancer-related fatigue. Physical Therapy 90: 1135-1147.

7. Bouchard C, Shephard RJ 1994 Physical activity, fitness, and health: the model and key concepts. In: Human Kinetics Champaign (Lowe).

8. Braun V, Clarke V 2006 Using thematic analysis in psychology. Qualitative Research in Psychology 3: 77-101.

9. Cancer Research UK 2017 Soft Tissue Sarcoma Statistics available at http://www.cancerresearchuk.org/health-professional/cancer-statistics/statistics-by-cancertype/soft-tissue-sarcoma

10. Cella DF, Tulsky DS, Gray G, Sarafian B, Lloyd S, Linn E, Bonomi A, Silberman M, Yellen SB, Winicour P, Brannon J, Eckberg K, Purl S, Blendowski C, Goodman M, Barnicle M, Stewart I, McHale M, Bonomi P, Kaplan E, Taylor S, Thomas C, Harris J 1993 The Functional Assessment of Cancer Therapy (FACT) scale: Development and validation of the general measure. Journal of Clinical Oncology 11: 570-579. 
11. Cheville AL, Rhudy L, Basford JR, Griffin J, Flores AM 2017 How receptive are patients with late stage cancer to rehabilitation services and what are the sources of their resistance? Archives of Physical Medicine and Rehabilitation 98: 203-210

12. Cheville AL, Kollasch J, Vandenberg J, Shen T, Grothey A, Gamble G, Basford JR 2013 A home-based exercise program to improve function, fatigue and sleep quality in patients with stage IV lung and colorectal cancer: a randomized controlled trial. Journal of Pain and Symptom Management 5:811-821

13. Conn VS, Hafdahl AR, Porock DC 2006 A meta-analysis of exercise interventions among people treated for cancer. Supportive Cancer Care 14: 699-712.

14. Courneya KS, Friedenreich CM 2011 Physical activity and cancer: introduction. In Courneya KS, Friedenreich CM Physical activity and cancer: recent results in cancer research, pp 1-10 Berlin: Springer. (Accessed: $21^{\text {st }}$ July 2014)

15. Courneya KS, Friedenreich CM 2007 Physical activity and cancer control. Seminars in Oncology Nursing 23: 242-252.

16. Courneya KS, Friedenreich CM, Quinney HA, Fields AL, Jones LW, Vallance KH, Fairey AS 2005 A longitudinal study of exercise barriers in colorectal cancer survivors 
participating in a randomised controlled trial. Annals of Behavioural Medicine 29:

147-153.

17. Cramp F, Daniel J 2008 Exercise for the management of cancer-related fatigue in adults. Cochrane Database of Systematic Reviews (2) DOI:

10.1002/14651858.CD006145.pub2.

18. Custodio C M 2007 Barriers to rehabilitation of extremity soft tissue sarcomas Journal of Surgical Oncology 95: 393-399.

19. Dahele M, Skipworth RJE, Wall L, Voss A, Preston T, Fearon KCH 2007 Objective physical activity and self-reported quality of life in patients receiving palliative chemotherapy. Journal of Pain and Symptom Management 33: 676-685.

20. Department of Health 2013 Living with and beyond cancer: taking action to improve outcomes Available at: https://www.gov.uk/government/publications/living-withand-beyond-cancer-taking-action-to-improve-outcomes (Accessed: 29th December 2014)

21. Department of Health 2011 Start Active, Stay Active: A report on physical activity for health from the four home countries. [Online] Available at: 
https://www.gov.uk/government/publications/start-active-stay-active-a-report-onphysical-activity-from-the-four-home-countries-chief-medical-officers (Accessed: $15^{\text {th }}$ August 2015) Published 11 July 2011 Last updated 11 March 2016

22. Department of Health 2009 Help and advice for living well with a long term condition. Available at: http://webarchive.nationalarchives.gov.uk/20100604145436/http://www.dh.gov.uk/ en/Publicationsandstatistics/Publications/PublicationsPolicyAndGuidance/DH_10299 6

23. Department of Health 2007 Cancer Reform Strategy. Available at: http://webarchive.nationalarchives.gov.uk/20071227120000/http://www.dh.gov.uk/ en/Publicationsandstatistics/Publications/PublicationsPolicyAndGuidance/DH_08100 6.html

24. Department of Health 2000 The NHS Cancer Plan. Available at:

http://webarchive.nationalarchives.gov.uk/+/www.dh.gov.uk/en/Publicationsandstat istics/Publications/PublicationsPolicyandGuidance/DH_4009609 (Accessed 3rd January 2015) 
25. Ekblom-Bak E, Ekblom B, Vikstrom M, De Faire U, Hellenius M 2012 The importance of non-exercise physical activity for cardiovascular health and longevity. British Journal of Sports 48: $233-8$

26. England R, Maddocks M, Manderson C, Wilcock A 2012 Factors influencing exercise performance in thoracic cancer. Respiratory Medicine 106: 294-9.

27. Ferriolli E, Skipworth RJ, Hendry P, Scott A, Stensteth J, Dahele M, Wall L, Greig C, Fallon M, Strasser F, Preston T, Fearon M 2012 Physical activity monitoring: a responsive and meaningful patient-centered outcome for surgery, chemotherapy or radiotherapy? Journal of Pain and Symptom Management 43: 1025-1035.

28. Friedenreich CM, Gregory J, Kopciuk KA, Mackey, JR, Courneya, KS 2009 Prospective cohort study of lifetime physical activity and breast cancer survival. International Journal of Cancer 124: 1954-62.

29. Gralla RJ, Hollen PJ, Msaouel P, Vincent Davis B, Petersen J 2014 An evidence-based determination of issues affecting quality of life and patient-reported outcomes in lung cancer. Results of a survey of 660 patients. Journal of Thoracic Surgery 9:12431248 
30. Granda-Cameron C, Hanlon AL, Lynch MP, Houldin A 2011 Experience of newly diagnosed patients with sarcoma receiving chemotherapy.Oncology Nursing Forum 38:160-169.

31. Granger CL, Connolly B, Denehey L, Hart N, Antippa P, Lin K, Parry SM 2017 Understanding factors influencing physical activity and exercise in lung cancer: a systematic review. Supportive Care in Cancer 25: 983-999

32. Green J,Thorogood N 2014 Qualitative methods for health research, $3^{\text {rd }}$ edn. London, Sage Publications.

33. Heywood R, McCarthy AL, Skinner TL 2018 Efficacy of exercise interventions in patients with advanced cancer: A systematic review. Archives of Physical Medicine and Rehabilitation doi.org/10.1016/i.apmr.2018.04.008

34. Hickson M 2008 Research handbook for health care professionals. Singapore, Blackwell Publishing.

35. Hoffman AJ, Britnall RA, Brown JK, von Eye A,Jones LW, Alderink G, Ritz-Holland D, Enter M, Patzelt LH, Van Otteren GM 2013 Too sick not to exercise: using a 6 week home-based exercise intervention for cancer-related fatigue self-management for post surgical non small-cell lung cancer patients. Cancer Nursing 36: 175-188 
36. Holloway I 2005 Qualitative Research in Healthcare. Maidenhead, Open University Press.

37. Holm LV, Hansen, DG, Larsen PV, Johansen C, Kragstrup 2012 Participation In cancer rehabilitation and unmet needs: a population-based cohort study. Supportive Care in Cancer 20: 2913-2924.

38. Irwin M, Crumley D, McTiernan A, Bernstein L, Baumgartner R, Gilliland F 2003 Physical activity levels before and after a diagnosis of breast carcinoma. Cancer 97: 1746-1757.

39. Jones LW, Hornsby WE, Goetzinger A, Forbes LM, Sherrard EL, Quist M, Lane AT, West M, Eves ND, Gradison M 2012 Prognostic significance of functional capacity and exercise behavior in patients with metastatic non-small cell lung cancer. Lung Cancer 76: $248-52$.

40. Kerry S, Courneya CM, Friedenreich H, Quinney A, Anthony LA, Fields LW, Jones JKH, Vallance MA, Fairey AS 2005 A Longitudinal Study of Exercise Barriers in Colorectal Cancer Survivors Participating in a Randomized Controlled Trial. Annals of Behavioural Medicine 29: 147-15. 
41. Knapen J, Vancampfort D, Moriën Y, Marchal Y 2015 Exercise Therapy improves both mental and physical health in patients with major depression. Disability and Rehabilitation 37: 1490-1495.

42. Knols R, Aronson NK, Uebelhart D 2005 Physical exercise in cancer patients during and after medical treatment: a systematic review of randomised and controlled clinical trials. Journal of Clinical Oncology 23: 3830-3842.

43. Kwong TNK, Furtado S, Gerrand C 2014 What do we know about survivorship after treatment for extremity sarcoma? A systematic review. European Journal of Surgical Oncology 40: 1109-1124.

44. Leiserowitz A, Watchie J. 2011 Exercise prescription. Topics in Geriatric Rehabilitation 27: 193-205.

45. Lemanne D, Cassileth B, Gubili J 2013 The role of physical activity in cancer prevention, treatment, recovery and survivorship. Oncology 27: 580-585

46. Liou YM, Lee H, Chien L, Kao W, Chiang C, Wang D 2011 Daily life physical activity and related factors among patients with cancer receiving chemotherapy in Taiwan. Cancer Nursing 34: 443-452. 
47. Lowe SS, Watanabe SM, Baracos YE, Courneya K S 2012 Determinants of physical activity in palliative cancer patients: an application of the theory of planned behaviour. Journal of Supportive Oncology 10: 30-36.

48. Lowe SS, Watanabe SM, Baracos YE, Courneya K 2010 Physical activity interests and preferences in palliative cancer patients. Supportive Care Cancer 18: 1469-1475.

49. Macmillan 2012 The importance of physical activity for people living with and beyond cancer. Available at:

http://www.macmillan.org.uk/Documents/AboutUs/Commissioners/Physicalactivitye videncereview.pdf (Accessed: 29 December 2014)

50. Macmillan 2015 The burden of cancer and other long-term conditions. Available at https://www.macmillan.org.uk/documents/press/cancerandotherlongtermconditions.pdf

51. Macmillan 2016 What motivates people with cancer to get active? Available at http://be.macmillan.org.uk/Downloads/CancerInformation/LivingWithAndAfterCance r/MAC16027-Physical-Activity-evidence-reviewREPORT-(A4)AWDIGITAL.pdf 
52. Maddocks M, Mockett S, Wilcock A 2009 Is exercise an acceptable and practical therapy for people with or cured of cancer? A systematic review. Cancer Treatment Review 35: 383-390.

53. Maddocks M, Granger C 2017 Lower limb muscle function and exercise performance in lung cancer. Respirology 22: 1053-4.

54. Malterud K, Siersma VD, Guassora AD 2016 Sample size in qualitative interview studies: guided by information power. Qualitative Health Research 26: 1753-1760

55. Midtgaard J, Rorth M, Stelter R, Adamsen L 2006 The group matters: an explorative study of group cohesion and quality of life in cancer patients participating in physical exercise intervention during treatment. European Journal of Cancer Care 15: 25-33.

56. Mijwel S, Cardinale DA, Norrbom J, Chapman M,Ivarsson N, WengstromY, Sundberg CJ, Rundqvist H 2018 Exercise training during chemotherapy preserves skeletal muscle fiber area, capillarization, and mitochondrial content in patients with breast cancer. The FASEB Journal

57. Mikkelsen T, Sondergaard J, Solowski CL, Jensen A, Olsen F 2009 Cancer survivors' rehabilitation needs in a primary health care context. Family Practice 26: 221-230. 
58. Milbury K, Mallaiah S, Lopez G, Liao Z, Yang C, Carmack C, Chaoul A, Spelman A, Cohen L 2015 Vivekananda yoga program for patients with advanced lung cancer and their family caregivers. Integrative Cancer Therapies 14: 446-451

59. Mishra SI, Schrerer RW, Geigle PM, Berlanstein DR, Topaloglu O 2012 Exercise interventions on health-related quality of life for cancer survivors. Cochrane Database Systematic Review. 10.1002/14651858.CD008465.pub2

60. NHS England 2014 Five year forward view. https://www.england.nhs.uk/wpcontent/uploads/2014/10/5yfv-web.pdf

61. NHS England 2016 Achieving world class cancer outcomes: taking the strategy forward https://www.england.nhs.uk/wp-content/uploads/2016/05/cancerstrategy.pdf

62. O’Donovan G, Blazevich AJ, Boreham C, Cooper AR, Crank A, Ekelund U, Fox KR, Gately P, Giles-Corti B, Gill JMR, Hamer M, McDermott I, Murphy M, Mutri M, Reilly JJ, Saxton JM, Stamatakis E 2010 The ABC of physical activity for health: a consensus statement from the British Association of Sport and Exercise Science. Journal of Sports Science 28: 573-591. 
63. Oeschle K, Jensen W, Schmidt T, Reer R, Braumann K, De Wit M, Bokemeyer C 2011 Physical activity, quality of life, and the interest in physical exercise programs in patients undergoing palliative chemotherapy. Supportive Care in Cancer 19: 613-619.

64. Oken MM, Creech RH, Tormey DC, Horton J, Davies TE, McFadden ET, Carbone PP 1982 Toxicity and response criteria of the Eastern Cooperative Oncology Group. American Journal of Clinical Oncology 5: 649-655

65. Oldervoll LM, Loge JH, Lydersen S, Paltiel H, Asp MB, Nygaard UV, Hjermstad MJ, Haugen DF, Paulsen O, Kaasa S 2011 Physical exercise for cancer patients with advanced disease: a randomised controlled trial. The Oncologist 16: 1649-1657.

66. Paltiel H, Solvoll E, Havard-Loge J, Kaasa S, Oldervoll L 2009 The healthy me appears: palliative cancer patients experiences of participation in a physical group exercise program. Palliative and Supportive Care 7: 459-467.

67. Parsons JA, Davis AM 2004 Rehabilitation and quality of life issues in patients with extremity soft tissue sarcoma. Current Treatment Options in Oncology 5: 477-488.

68. Pate RRM, Pratt SN, Blaire WL, Haskell CA, Macera C 1995 Physical activity and public health: recommendation from the Centre for Disease Control and Prevention and the 
American College of Sports Medicine. Journal of the American Medical Association 273: $402-407$.

69. Patton MQ 1990 Qualitative Evaluation and Research Methods, $2^{\text {nd }}$ edn. London: Sage Publishing.

70. Public Health England 2010 Soft Tissue Sarcomas: incidence and survival rates in England. Available at:

http://www.ncin.org.uk/publications/data briefings/soft tissue sarcoma (Accessed:

4 January 2014)

71. Quist M, Rorth M, Zacho M, Andersen C, Moeller T, Midtgaard J, Adamsen L 2006 High-intensity resistance and cardiovascular training improve physical capacity in cancer patients undergoing chemotherapy. Scandinavian Journal of Medicine \& Science in Sports 16: 349-57

72. Quist M, Rorth M, Langer S, Jones LW, Laursen JH, Pappot H, Christensen KB, Adamsen L 2012 Safety and feasibility of a combined exercise intervention for inoperable lung cancer patients undergoing chemotherapy: a pilot study. Lung Cancer 75: $203-8$

73. Quist M, Langer SW, Rorth M, Christensen KB, Adamsen L. EXHALE: exercise as a strategy for rehabilitation in advanced stage lung cancer patients: a randomized 
clinical trial comparing the effects of 12 weeks supervised exercise intervention versus usual care for advanced stage lung cancer patients. BMC Cancer. 2013;13:477.

74. Rogers LQ, Matevey C, Hopkins-Price P, Shah P, Dunnington G, Courneya KS 2004 Exploring social cognitive theory constructs for promoting exercise among breast cancer patients. Cancer Nursing 27: 462-473.

75. Saxton JM, Daley AJ 2010 Exercise and cancer survivorship: impact on health outcomes and quality of life. New York: Springer.

76. Schmitz KH, Courmeya KS, Mathews C, Demark-Wahnefried W, Galva D, Pinto, BM, Irwin M, Wolin KY, Segal RJ, Lucia A, Schneider CM, von Gruenigen VE, Schwartz A 2010 American College of Sports Medicine Roundtable on Exercise Guidelines for Cancer Survivors American College of Sports Medicine: 1409-1426.

77. Schreiber D, Bell, RS, Wunder JS, O’Sullivan B, Turcotte R, Masri BA, Davis AM 2006 Evaluating function and health related quality of life in patients treated with extremity soft tissue sarcoma. Quality of Life Research 15: 1439-1446.

78. Small ML 2009 How many cases do I need? Ethnography. http://journals.sagepub.com/doi/pdf/10.1177/1466138108099586 link OK 27.12.17 
79. Talbot-Rice H, Malcolm L, Norman K, Jones A, Lee K, Preston G, McKenzie D, Maddocks M 2014 An evaluation of St Christopher's Hospice rehabilitation gym circuit classes: patient uptake, outcome and feedback. Progress in Palliative Care 22: 319-325.

80. Thomas RJ, Kenfield SA, Jimenez A 2016 Exercise-induced biochemical changes and their potential influence on cancer: a scientific review. British Journal of Sports Medicine.

81. Tobias K, Gillis T 2014 Rehabilitation of the Sarcoma Patient - Enhancing the Recovery and Functioning of Patients Undergoing Management for Extremity Soft Tissue Sarcomas. Journal of Surgical Oncology 111: 615-621.

82. Tong A, Sainsbury P, Craig J 2007 Consolidated criteria for reporting qualitative research (COREQ): a 32 item checklist for interviews and focus groups. International Journal for Quality in Health Care 19: 349-357.

83. Vallance JKH, Courneya KS, Jones LW, Reiman T 2006 Exercise preferences among a population-based sample of non-Hodgkins lymphoma patients. European Journal of Cancer Care 15: 34-43. 
84. Varpio L, Ajjawi R, Monrouxe LV, O’Brien BC, Rees CE 2017 Shedding the cobra effect: problematising thematic emergence, triangulation, saturation and member-checking. Medical Education 51: 40-50

85. Wagland R, Richardson A, Ewings S, Armes J, Lennan E, Hankins M 2016 Prevalence of cancer chemotherapy-related problems, their relation to health-related quality of life and associated supportive care: a cross-sectional survey. Supportive care in cancer: official journal of the Multinational Association of Supportive Care in Cancer 24: 4901-11.

86. Walsh JM, Hussey J, Guinan E, O’Donnell D 2010 Pragmatic randomised controlled trial of individually prescribed exercise versus usual care in a heterogenous cancer survivor population: a feasibility study PEACH trial: prescribed exercise after chemotherapy. BioMed Central 10: 1-7.

87. Wilkinson S, Joffe H, Yardley L 2004 Qualitative data collection: interviews and focus groups. In: Marks DF, Yardley, L (eds) Research methods for clinical and health psychology 39-54. London, Sage.

88. Wolin KY, Schwartz AL, Matthews CE, Courneya K S Schmitz KH 2012 Implementing the Exercise Guidelines for Cancer Survivors 10: 171-177.

89. World Health Organisation 2004 Global strategy on diet, physical activity and health World Health Organisation. Available at: http://www.who.int/dietphysicalactivity/factsheet recommendations/en/ 


\section{ACKNOWLEDGEMENTS}

With thanks to the patients and the Sarcoma Unit at the RMNHSFT for supporting this study. With particular thanks to Dr Charlotte Benson and Professor lan Judson, Lindsey Bennister from Sarcoma UK for collaboration and advice about the interview topic schedule, the RM Therapies Department and the sarcoma clinical nurse specialists for support during the development and conduct of this study; also Professor Theresa Wiseman for on-going support and advice. The authors acknowledge support from the National Institute for Health Research (NIHR) Royal Marsden/Institute of Cancer Research Biomedical Research Centre.

\section{DECLARATION OF INTEREST}

The authors declared no potential conflicts of interest with respect to the research, authorship and/or publication of this article. 